\title{
Effects of dietary supplementation with Bacillus subtilis and yeast culture on growth performance, nutrient digestibility, serum indices and faeces microbiota of weaned piglets
}

\author{
K. Cui, X. Iv, Q. Diao and N. Zhang ${ }^{1}$ \\ Feed Research Institute, Chinese Academy of Agricultural Sciences, Beijing 100081, China
}

KEY WORDS: Bacillus subtilis, microbial flora, piglets, weaning, yeast culture

Received: 27 December 2018

Revised: 13 September 2019

Accepted: 2 December 2019

\footnotetext{
${ }^{1}$ Corresponding author:

e-mail: zhangnaifeng@caas.cn
}

\begin{abstract}
The aim of this study was to investigate the effects of Bacillus subtilis and yeast culture (YC) on growth performance, nutrient digestibility, serum biochemical and immunological parameters and microbial community of weaned pigs. One hundred and ninety-two weaned piglets (Large White $\times$ Landrace, 96 males and 96 females) with an average initial body weight of $8.22 \pm 1.46 \mathrm{~kg}$ were randomly divided into 4 groups ( 8 piglets per pen, 6 pens per group). Piglets in the control group were fed a basal diet with $1 \mathrm{~g} / \mathrm{kg}$ of bacitracin zinc and the others were fed basal diets supplemented with $1 \mathrm{~g} / \mathrm{kg}$ of solid-state products containing $10^{10} \mathrm{CFU} / \mathrm{g}$ of $B$. subtilis or $3 \mathrm{~g} / \mathrm{kg}$ of $\mathrm{YC}$ with live yeast (Saccharomyces cerevisiae) cells of $4.5 \times 10^{6} \mathrm{CFU} / \mathrm{g}$ or the combination of two above mentioned supplements. Pigs were fed the experimental diets for 41 days. There was no significant difference in body weight and feed intake of piglets between control and other experimental groups. In comparison to the control group, the ether extract digestibility was increased in all supplemented group, and the $P$ digestibility was decreased only in $B$. subtilis group. The supplementation with $B$. subtilis and/or $Y C$ did not affect either serum biochemical or immunological parameters in comparison to the control group. Also, the similar effect on faecal microbiota composition was stated in the supplemented groups and control one. B. subtilis or YC could be used as a substitute for antibiotics and so be applied to the rearing of weaned piglets. However, the usage of their combination in the examined proportion does not enhance the effect.
\end{abstract}

\section{Introduction}

Piglets weaning from sows are subjected to such stressors as diarrhoea, low feed intake and body weight loss, which reduce their immune response and disturb the equilibrium of the intestinal microflora owing to their immature immune and digestive systems (Alexopoulos et al., 2004; Ren et al., 2014). The antibiotic supplementation into feed for a long period may solve post-weaning problems, prevent animals from infectious diseases and improve the growth performance, and so it has turned into a global practice (Barton, 2000). The benefits of antibiotics in terms of efficiency in the gain of body weight, decrease in mortality and morbidity and reduction in the occurrence of subclinical diseases were observed during all phases of pig growth (Chattopadhyay, 2014). However, the widespread use of antibiotics has led to the emergence of drugresistant bacteria, which will have a major health hazard to human health (Rather et al., 2012). Therefore, many countries have begun to ban the use of antibiotics in animal feed only to promote animal growth (Millet and Maertens, 2011). 
As the most preferred and effective alternative for antibiotics in animal feeding, probiotics have been proved to have the beneficial effects on growth performance, nutrient retention and mortality and so they are widely used in poultry and livestock industry (Wang and Gu, 2010). Probiotics are live cultures of beneficial bacteria or yeast species which could compete with harmful gut flora colonization, maintain the gut integrity and stimulate the immune system of the host to increase the resistance to infectious agent (Benyacoub et al., 2003). Bacillus subtilis has demonstrated probiotic characteristics of pathogens inhibition and spore's high resistance to harsh conditions in the digestive tract of the host (Hung et al., 2012). Li et al. (2016) proved that B. subtilis could effectively improve the growth performance and feed conversion ratio (FCR) of broilers via the beneficial modulation of caecal microbiota. Recent studies showed that direct feeding of $B$. subtilis to pigs improved growth performance, nutrient digestibility, immune response and caecal microbiota (Lee et al., 2014; Canning et al., 2017). However, the effect of probiotics on the digestibility of protein and amino acids, and performance was varied with the energy density of diets (Kaewtapee et al., 2017).

Yeast culture is a dried product containing yeast and various metabolites of yeast fermentation. Previous studies indicate that yeast culture is a good candidate to be an antibiotic alternative improving growth performance and modulating gut immune response in weaned piglets (Shen et al., 2009; Trckova et al., 2014). Dietary supplementation of yeast culture has been proved to improve milk production of cows and growth performance of weaning pigs (Hansen et al., 2017; Kiros et al., 2018). However, in some studies it was reported that the addition of yeast culture did not affect the average daily gain (ADG), average daily feed intake (ADFI) or FCR of piglets and modified yeast culture (yeast culture + cell wall product (CWP) containing mannan oligosaccharides) would not improve the performance or health of weanling pigs (PeetSchwering et al., 2007).

Since the results of studies on the supplementation of $B$. subtilis and yeast culture products in pig nutrition are inconsistent, and the number of studies on the combined effects of $B$. subtilis and yeast culture in pigs is limited, the subject of the present study seems to be fully justified. Thus, the purpose of this study was to investigate the effects of $B$. subtilis, yeast culture and their combination on growth efficiency, nutrient digestibility and serum indicators in weaned piglets, and on the composition and diversity of faecal microflora studied with the use of highthroughput next-generation sequencing.

\section{Material and methods}

The research was conducted at the Fang Shan pig breeding farm (Beijing, China; latitude $39.67^{\prime} \mathrm{N}$, longitude $\left.116.19^{\prime} \mathrm{E}\right)$. The Chinese Academy of Agricultural Sciences Animal Ethics Committee approved the experimental protocol (AEC-CAAS-2017-03), and humane animal care and handling procedures were followed throughout the experiment.

\section{Animals, diets and management}

One hundred and ninety-two weaned piglets (Large White $\times$ Landrace, 96 males and 96 females) with an average initial body weight of $8.22 \pm 1.46 \mathrm{~kg}$ were randomly divided into fourgroups: (1) CON: piglets fed basal diet and $1 \mathrm{~g} / \mathrm{kg}$ of bacitracin zinc (Zhongnongxing Feed Sci. \& Tech. Co., Ltd, Beijing, China); (2) BS: piglets fed basal diet and $1 \mathrm{~g} / \mathrm{kg}$ of solid-state products containing $10^{10} \mathrm{CFU} / \mathrm{g}$ of B. subtilis; (3) YC: piglets fed basal diet and $3 \mathrm{~g} / \mathrm{kg}$ of yeast culture with live yeast (Saccharomyces cerevisiae) cells of $4.5 \times 10^{6} \mathrm{CFU} / \mathrm{g}$; (4) BY: piglets fed basal diet supplemented with $1 \mathrm{~g} / \mathrm{kg}$ of solid-state products containing $10^{10} \mathrm{CFU} / \mathrm{g}$ of B. subtilis and $3 \mathrm{~g} / \mathrm{kg}$ of yeast culture. The $B$. subtilis and yeast culture were acquired from Huanong Biological engineering Co., Ltd. (Beijing, China). Each group had six replicates with eight piglets in each replicate. The basal diet was formulated according to the nutrient requirements of National Research

Table 1. Composition and nutrient level of the basal diet, dry matter basis

\begin{tabular}{ll}
\hline Indices & Content \\
\hline Ingredients & \\
maize & 60 \\
soybean meal & 25 \\
wheat bran & 3 \\
concentrate supplement $^{\text {a }}$ & 8 \\
premix $^{\text {b }}$ & 4 \\
Nutrient content ${ }^{\mathrm{c}}$ & \\
DM & 90.76 \\
CP & 18.46 \\
ME, MJ/kg & 16.57 \\
EE & 4.03 \\
Ash & 7.31 \\
Calcium & 1.07 \\
Phosphorus & 0.42 \\
\hline
\end{tabular}

${ }^{a}$ the concentrate used in this research was the milk replacer involved in patent (not open to the public); ${ }^{b}$ the premix provided the following nutrients per kg of the diet: IU: vit. A 5512, vit. D 640, vit. $\mathrm{K}_{3} 2.2$, vit. E 20; mg: vit. $B_{1} 1.5$, vit. $B_{2} 5.5$, vit. $B_{6} 2.2$, D-pantothenic acid 14.8 , nicotinic acid 30.3, biotin 0.05 , choline 500 , Cu 50, Fe 100, Mn 10, Zn 50, I 0.85, Se $0.25 ; \mu g$ : vit. $B_{12} 27.6$; ${ }^{\circ}$ nutrient levels are all measured values except ME that was calculated; DM - dry matter; $\mathrm{CP}$ - crude protein; $\mathrm{ME}$ - metabolic energy; $\mathrm{EE}$ - ether extract 
Council (NRC, 2012). Feed and water were available ad libitum during the 41-day feeding period. The ingredients and chemical composition of the diet are presented in Table 1. Feed intake and body weight were measured at the beginning and end of the experiment to calculate ADG, feed intake (FI) and FCR.

\section{Faeces and feed samples}

The nutrient digestion trial was conducted during the last 5 days of the study. The feed samples were collected before morning feeding. Approximately $200 \mathrm{~g}$ of faecal samples were collected from each pen into sterile plastic bottles. The faecal samples were collected twice daily for 5 following days. The 5-day samples were homogenized and $500 \mathrm{~g}$ faecal sample of the total was collected and stored at $-20^{\circ} \mathrm{C}$ for further analysis of nutrient content. Digestibility estimates were measured using the indicator (acid-insoluble ash, AIA) method according to the procedure of Favero et al. (2014).

\section{Chemical analyses}

Chemical analyses were performed as it was described before (Favero et al., 2014). The dry matter (DM) was determined by the method of AOAC (1990). The gross energy (GE) was determined by an automatic adiabatic oxygen bomb calorimeter (C200; IKA Works Inc., Staufen, Germany). The nitrogen $(\mathrm{N})$ content was determined by the Kjeldahl method, with selenium (Se) as a catalyst, and crude protein $(\mathrm{CP})$ content was calculated as $6.25 \times \mathrm{N}$ (method 984.13; AOAC, 1990). The contents of ash (method 942.05), ether extract (EE; method 920.39), phosphorus (P; method 965.17) and calcium $(\mathrm{Ca}$; method 968.08) were conducted according to the methods of AOAC (1990).

\section{Blood samples}

Blood samples were collected before morning feeding at the end of trial by precava venipuncture into 10-ml vacuum tube (Tianming Medical Instrument Co., Ltd, Jiangxi, China). The samples were centrifuged $\left(5000 \mathrm{~g}, 20 \mathrm{~min}, 4{ }^{\circ} \mathrm{C}\right)$ to obtain the serum which was frozen at $-20^{\circ} \mathrm{C}$ until further analysis. The serum biochemical parameters such as total protein (TP), alkaline phosphatase (ALP), blood urea N (BUN), glucose (GLU), cholesterol (CHO), immunoglobulin $\mathrm{G}$ (IgG), immunoglobulin A (IgA) and immunoglobulin $\mathrm{M}(\operatorname{IgM})$ were detected by an automatic biochemical analyser (Hitachi 7160; Hitachi Limited, Tokyo, Japan) at the Centre for Clinical Laboratory Development of the Chinese Academy of Medical Sciences (Beijing, China).

\section{Microbial analysis}

DNA extraction, PCR amplification of $16 \mathrm{~S}$ rRNA and Hiseq sequencing. The faecal samples were collected from each pen via rectal massage, and microbial DNA was extracted using a commercially available kit (Omega Bio-tek, Norcross, GA, USA). The amplification and sequencing were conducted in Total Genomics Solution Technology Co., Ltd. (Shenzhen, China). The V3-V4 regions of the bacterial 16S ribosomal RNA genes were amplified using primers $341 \mathrm{~F}$ (5'-barcode-CCTAYGGGRBGCASCAG)-3' and 806R (5'-GGACTACCVGGGTATCTAAT-3'), where barcode is an eight-base sequence unique to each sample. Amplicons were pooled in equimolar and paired-end sequenced $(2 \times 250)$ on an Illumina HiSeq platform after the purification using the AxyPrep DNA Gel Extraction Kit (Axygen Biosciences, Union City, CA, USA) and quantification using QuantiFluorTM -ST (Promega, Madison, WT, USA).

\section{Statistical and bioinformatics analysis}

The effective tags were obtained after demultiplexed and quality filtered using the Quantitative Insights into Microbial Ecology (QIIME, v.1.8.0; Caporaso et al., 2010) and clustered into operational taxonomic units (OTU) by $97 \%$ similarity using UPARSE (version 7.1; Edgar, 2013). The $\alpha$ diversity and $\beta$ diversity calculations were performed using QIIME. Taxonomic assignments of OTUs at 97\% similarity level were conducted by QIIME against RDP (16S, http://rdp.cme.msu.edu/) database using confidence threshold of $80 \%$. Variations in different groups were analysed using the SAS statistical software package (version 9.1, 2004; SAS Institute, Inc., Cary, NC, USA). The significance level was set at 0.05 .

\section{Results}

\section{Growth performance}

There was no significant effect of $B$. subtilis or/and yeast culture supplementation on final body weight, ADG, FI and FCR in comparison to group fed diet with antibiotic $(P>0.05$; Table 2$)$. As compared to the CON group, the ADG of piglets in BS, YC and BY groups increased and were 14.14, 13.27 and $9.51 \%$, respectively, but the differences were not significant.

\section{Nutrient digestibility}

The effects of supplementation of B. subtilis or/ and yeast culture on digestibility of pigs are shown 
Table 2. Effect of supplementation with Bacillus subtilis and yeast culture on growth performance of weaned piglets

\begin{tabular}{lccccccc}
\hline \multirow{2}{*}{ Indices } & \multicolumn{3}{c}{ Groups $^{1}$} & & & & \\
\cline { 2 - 6 } & CON & BS & YC & BY & & & \\
\hline Initial body weight, kg & 8.2 & 8.3 & 8.3 & 8.1 & 0.99 & 0.9993 \\
Final body weight, kg & 22.2 & 24.3 & 24.2 & 23.5 & 2.04 & 0.8807 \\
Average daily gain, g & 343 & 391 & 388 & 375 & 30.97 & 0.6841 \\
Feed intake, g & 795 & 864 & 873 & 843 & 63 & 0.8181 \\
Feed conversion ratio & 2.32 & 2.23 & 2.25 & 2.24 & 0.08 & 0.8533 \\
\hline
\end{tabular}

1 groups: CK - control group, BS - Bacillus subtilis supplemented group, YC - yeast culture supplemented group, BY - both Bacillus subtilis and yeast culture supplemented group; ${ }^{2}$ feed conversion ratio $=$ feed intake $(\mathrm{kg}) /$ total body weight gain $(\mathrm{kg})$

in Table 3. The supplementation of B. subtilis, yeast culture or their combination increased the digestibility of $\mathrm{EE}$, but the digestibility of $\mathrm{P}$ was decreased in $\mathrm{BS}$ group in comparison to $\mathrm{CON}$ group $(P<0.05)$. The digestibility of DM, organic matter $(\mathrm{OM})$, ash and $\mathrm{Ca}$ tended to be lower in $\mathrm{BS}$ and $\mathrm{YC}$ groups than those in the CON group $(0.05<P<0.1)$. No significant difference was observed in GE and $\mathrm{CP}$ digestibility among all groups $(P>0.05)$.

\section{Blood metabolites and immune indices}

There was no significant effect of B. subtilis, yeast culture or their combination supplementation on examined blood metabolites: TP, ALP, GLU, $\mathrm{CHO}$ and BUN, as well as on immune indices in comparison to control group fed diet with commercial antibiotic addition $(P>0.05$; Table 4$)$.

\section{Microbial community}

The species accumulation curves indicated that sampling had sufficient sequence coverage to ac-

Table 3. Effect of supplementation with Bacillus subtilis and yeast culture on nutrient digestibility of weaned piglets

\begin{tabular}{lllllll}
\hline Indices & \multicolumn{3}{l}{ Groups $^{1}$} & & & \\
& \cline { 3 - 5 } CON & BS & YC & BY & SEM & -value \\
\hline GE, \% & 88.2 & 86.6 & 86.1 & 87.5 & 1.42 & 0.1377 \\
DM, \% & 88.9 & 86.9 & 86.6 & 87.6 & 1.34 & 0.0577 \\
OM, \% & 90.1 & 88.0 & 87.8 & 88.4 & 1.36 & 0.0580 \\
CP, \% & 86.2 & 84.8 & 83.8 & 86.2 & 1.73 & 0.1098 \\
EE, \% & $55.7^{\mathrm{b}}$ & $67.6^{\mathrm{a}}$ & $68.0^{\mathrm{a}}$ & $69.0^{\mathrm{a}}$ & 7.41 & 0.0138 \\
Ash, \% & 72.8 & 67.7 & 68.6 & 71.8 & 3.34 & 0.0701 \\
$\mathrm{Ca}, \%$ & 75.0 & 69.7 & 73.7 & 79.4 & 5.57 & 0.0866 \\
$\mathrm{P}, \%$ & $64.0^{\mathrm{a}}$ & $54.4^{\mathrm{b}}$ & $57.0^{\mathrm{ab}}$ & $60.7^{\mathrm{ab}}$ & 5.24 & 0.0458 \\
\hline
\end{tabular}

GE - gross energy; DM - dry matter; OM - organic matter; $\mathrm{CP}$ - crude protein, $\mathrm{EE}$ - ether extract; $\mathrm{Ca}$ - Calcium; $\mathrm{P}$ - Phosphorus; ${ }^{1}$ groups: CON - control group, BS - Bacillus subtilis supplemented group, YC - yeast culture supplemented group, BY - both Bacillus subtilis and yeast culture supplemented group; ${ }^{\text {ab }}$ - means within the same row with the different superscript letters are significantly different $(P<0.05)$
Table 4. Effect of supplementation with Bacillus subtilis and yeast culture on serum biochemical indices of weaned piglets

\begin{tabular}{|c|c|c|c|c|c|c|}
\hline \multirow{2}{*}{ Indices } & \multicolumn{4}{|c|}{ Groups $^{1}$} & \multirow{2}{*}{ SEM } & \multirow{2}{*}{$P$-value } \\
\hline & $\overline{\mathrm{CON}}$ & BS & YC & $B Y$ & & \\
\hline $\mathrm{TP}, \mathrm{g} / \mathrm{l}$ & 65.2 & 65.9 & 66.2 & 70.9 & 8.60 & 0.7524 \\
\hline ALP, U/I & 217 & 206 & 204 & 191 & 30.17 & 0.6203 \\
\hline GLU, mmol/l & 2.80 & 3.03 & 3.68 & 3.84 & 0.86 & 0.1546 \\
\hline $\mathrm{CHO}, \mathrm{mmol} / \mathrm{l}$ & 2.42 & 2.23 & 2.29 & 2.59 & 0.42 & 0.5809 \\
\hline $\mathrm{BUN}, \mathrm{mmol} / \mathrm{l}$ & 7.56 & 7.29 & 7.28 & 7.60 & 1.01 & 0.9460 \\
\hline $\lg A, g / l$ & 0.99 & 0.89 & 1.20 & 1.01 & 0.25 & 0.2670 \\
\hline $\lg G, g / l$ & 8.56 & 8.37 & 8.49 & 8.98 & 0.75 & 0.6307 \\
\hline $\operatorname{lgM}, g / \operatorname{l}$ & 0.75 & 0.79 & 0.80 & 0.86 & 0.09 & 0.2146 \\
\hline
\end{tabular}

TP - total protein, ALP - alkaline phosphatase, GLU - glucose, $\mathrm{CHO}$ - carbohydrate; $\mathrm{BUN}$ - blood urea nitrogen; IgA-immunoglobulin $A$; IgG - immunoglobulin G; IgM - immunoglobulin $\mathrm{M}$; ${ }^{1}$ groups: CON - control group, BS - Bacillus subtilis supplemented group, $Y C$ - yeast culture supplemented group, BY - both Bacillus subtilis and yeast culture supplemented group

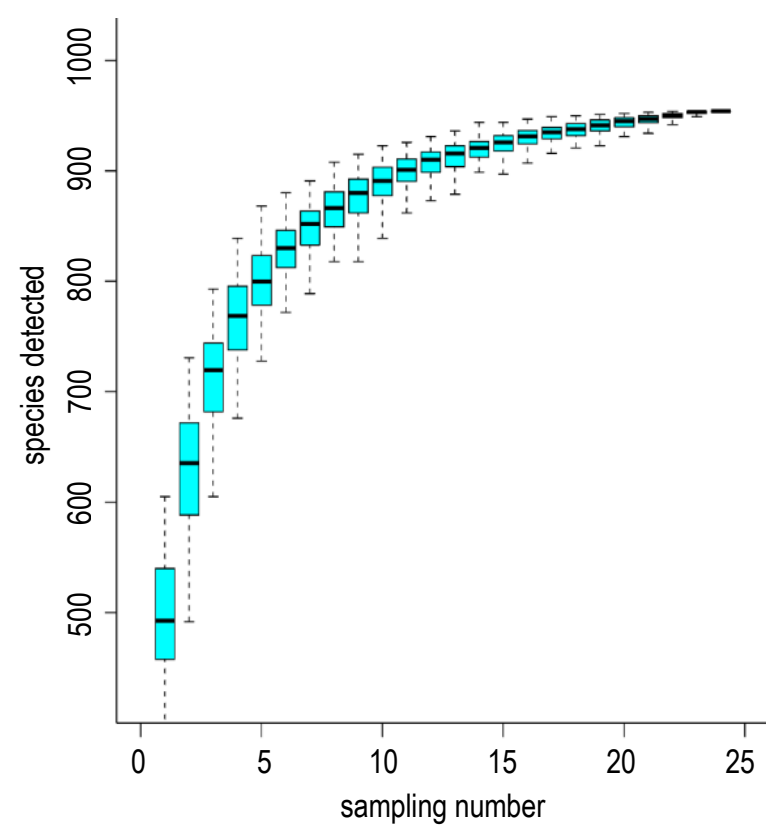

Figure 1. Species accumulation curves in faecal samples of piglets

curately describe the bacterial composition of each group (Figure 1). The OTUs identified among the four groups is shown in Figure 2. Based on the OTUs at the 0.03 dissimilarity level, the indices of bacterial richness and diversity were determined by the method of Chao and Shannon (Dong et al., 2017). It was shown that addition of $B$. subtilis or/and yeast culture allowed to achieve the same bacterial richness and diversity in faeces of piglets as in the $\mathrm{CON}$ group $(P>0.05$; Figure 2$)$.

Based on the SILVA taxonomic database, the effective tags were classified from phylum to species. A total of 18 different phyla were detected 

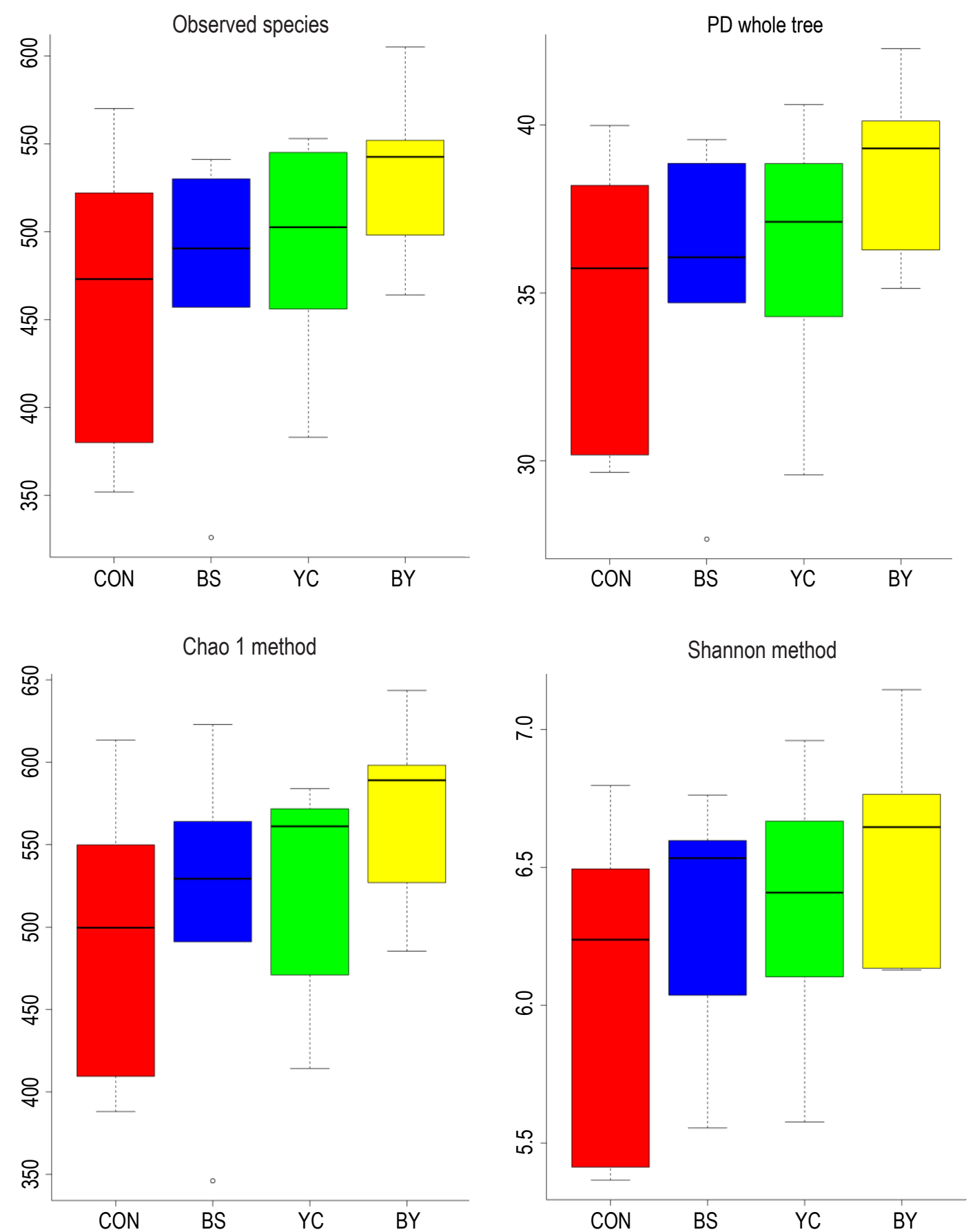

Figure 2. Community richness estimates and diversity indices for different treatments

in the examined samples (Figure 3; Table 5). The four groups showed very similar taxonomic compositions at the phylum-level distributions and the major sequences obtained from the samples belonged to Firmicutes and Bacteroidetes. In the control group with antibiotic addition, Firmicutes, Bacteroidetes and Proteobacteria were the dominant phyla and accounted for 51.3, 38.7 and 4.31 of the total reads, respectively. Within the BS group also Firmicutes (61.1\%), Bacteroidetes (30.1\%) and Proteobacteria (2.52\%) were the dominant phyla. The YC group was dominated by Firmicutes, Bacteroidetes and Actinobacteria, representing $61.6,28.0$ and $2.98 \%$ of the total reads, respectively. However, in the BY group (like in the CON and BS groups) Firmicutes, Bacteroidetes and Proteobacteria were the most common groups and accounted for $58.0,32.9$ and $2.42 \%$ of the total reads, respectively.

A total of 88 different genera were detected in the examined faecal samples (Figure 4; Table 6). Analysis of the microbiota composition at genus level 
Table 5. Effect of supplementation with Bacillus subtilis and yeast culture on the dominant phylum composition of weaned piglets, $\%$

\begin{tabular}{|c|c|c|c|c|c|c|}
\hline \multirow{2}{*}{ Indices } & \multicolumn{4}{|l|}{ Groups $^{1}$} & \multirow{2}{*}{ SEM } & \multirow{2}{*}{$P$-value } \\
\hline & $\overline{\mathrm{CON}} \quad \mathrm{B}$ & BS & YC & BY & & \\
\hline Firmicutes & 51.3 & 61.1 & 61.6 & 58.0 & 9.50 & 0.2145 \\
\hline Bacteroidetes & 38.7 & 30.1 & 28.0 & 32.9 & 9.92 & 0.2837 \\
\hline Proteobacteria & 4.31 & 2.52 & 2.83 & 2.43 & 2.42 & 0.5285 \\
\hline Euryarchaeota & 2.67 & 2.18 & 2.86 & 2.11 & 2.41 & 0.9444 \\
\hline Actinobacteria & 1.15 & 1.80 & 2.98 & 1.67 & 2.27 & 0.5812 \\
\hline Spirochaetes & 1.11 & 1.22 & 0.79 & 2.11 & 1.67 & 0.585 \\
\hline Tenericutes & 0.46 & 0.69 & 0.59 & 0.55 & 0.37 & 0.7784 \\
\hline Cyanobacteria & 0.12 & 0.12 & 0.14 & 0.08 & 0.08 & 0.6242 \\
\hline WPS-2 & 0.044 & 0.020 & 0.004 & 0.015 & 0.05 & 0.6085 \\
\hline Fibrobacteres & 0.057 & 0.033 & 0.022 & 0.029 & 0.04 & 0.5001 \\
\hline TM7 & 0.031 & 0.065 & 0.051 & 0.029 & 0.04 & 0.3149 \\
\hline Elusimicrobia & 0.0065 & 0.0024 & 0.0119 & 0.0075 & 0.01 & 0.7516 \\
\hline Chlamydiae & 0.0087 & 0.0022 & 0.0025 & 0.0018 & 0.01 & 0.2684 \\
\hline Deferribacteres & 0.0028 & 0.0043 & 0.0009 & 0.0020 & 0.01 & 0.7982 \\
\hline Synergistetes & 0.0041 & 0.0067 & 0.0023 & 0.0044 & 0.01 & 0.5441 \\
\hline Others & 0.054 & 0.080 & 0.053 & 0.075 & 0.05 & 0.7509 \\
\hline
\end{tabular}

${ }^{1}$ groups: CON - control group, BS - Bacillus subtilis supplemented group, YC - yeast culture supplemented group, BY - both Bacillus subtilis and yeast culture supplemented group

Table 6. Effect of supplementation with Bacillus subtilis and yeast culture on comparison of the dominant genus of weaned piglets, $\%$

\begin{tabular}{lrrrrrr}
\hline \multirow{2}{*}{ Indices } & \multicolumn{3}{l}{ Groups $^{1}$} & \multicolumn{4}{l}{ SEM } & P-value \\
\cline { 2 - 6 } & CON & BS & \multicolumn{1}{l}{ YC } & BY & & \\
\hline Prevotellaceae & 15.36 & 24.88 & 16.54 & 17.02 & 9.815 & 0.3336 \\
Megasphaera & 7.83 & 6.40 & 5.00 & 9.84 & 4.283 & 0.2458 \\
Dialister & 6.76 & 4.01 & 4.58 & 3.92 & 3.439 & 0.4689 \\
Ruminococcus & 0.87 & 1.00 & 4.09 & 2.14 & 3.104 & 0.2546 \\
Lactobacillus & 7.44 & 3.29 & 4.11 & 4.26 & 3.530 & 0.1842 \\
Oscillospira & 5.57 & 3.61 & 4.81 & 4.69 & 2.770 & 0.7072 \\
Methanobrevibacter & 2.82 & 2.63 & 2.07 & 2.12 & 2.379 & 0.9411 \\
Streptococcus & 1.18 & 1.42 & 2.50 & 2.60 & 1.786 & 0.4113 \\
Treponema & 0.78 & 1.11 & 2.11 & 1.21 & 1.669 & 0.5835 \\
Roseburia & 1.89 & 2.89 & 2.30 & 2.73 & 1.335 & 0.5924 \\
\hline
\end{tabular}

${ }^{1}$ groups: CON - control group, BS - Bacillus subtilis supplemented group, YC - yeast culture supplemented group, BY - both Bacillus subtilis and yeast culture supplemented group

indicated that the most dominant bacteria in faecal microbiota in all four groups were Prevotellaceae and Megasphaera. However, the third dominant genus was Lactobacillus in CON group, Dialister in BS group and Oscillospira in both YC and BY groups. Besides the numerical differences between groups, the usage of $B$. subtilis and yeast culture caused statistically similar values for all detected genera.

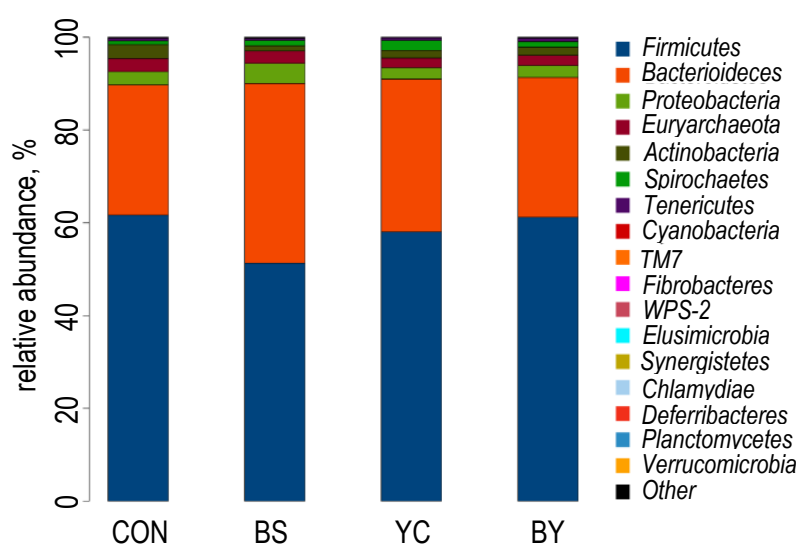

Figure 3. The bacterial composition at phylum level in faecal samples of piglets (colour-coded bar plots show the relative abundances of different phyla across different groups)

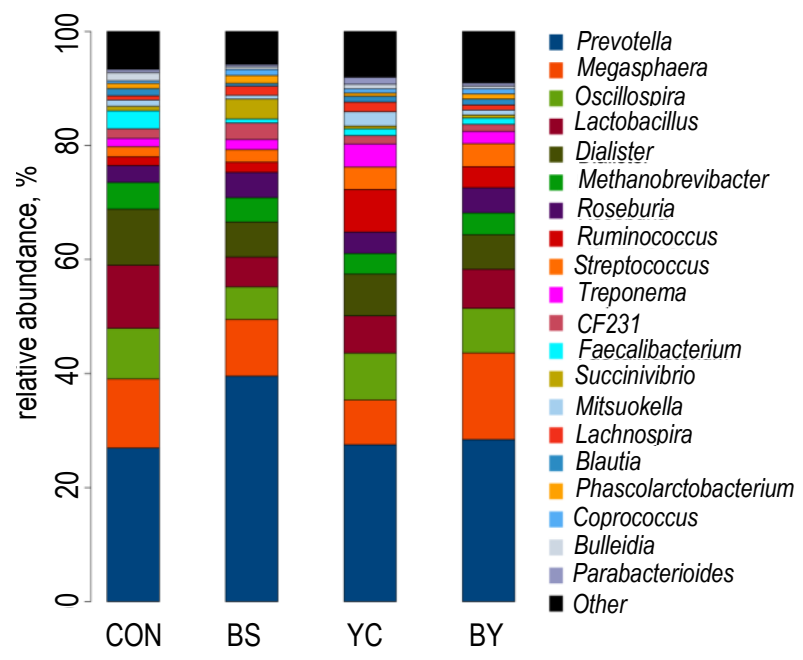

Figure 4. The bacterial composition at genus level in faecal samples of piglets (colour-coded bar plots show the relative abundances of different genera across different groups)

\section{Discussion}

Moore et al. (1946) were the first to discover that a low dose of antibiotics could promote the growth of chick, and the further studies with livestock showed the similar effects in swine and cattle. Addition of antibiotics to the feed was widely used in animal husbandry industry as an integral part of their feeding programmes. Spellberg et al. (2013) reported that 13 million $\mathrm{kg}$ of antibiotics were administered to animals and the majority of them were used as growth promoter of livestock. However, diseases that were thought to be fully controlled by antibiotics are now returning in new forms resistant to antibiotic treatment (Levy and Marshall, 2004). Evidences available in the literature speak volumes for the effective alternatives of probiotics for antibiotics in animal feeding.

As the members of probiotics, B. subtilis or yeast culture have the improving effect on the 
growth performance of broilers (Hung et al., 2012), pigs (Jørgensen et al., 2016) and lambs (Tripathi et al., 2008; Estrada-Angulo et al., 2013). The results obtained in the present study indicated that the addition of $B$. subtilis or yeast culture as the substitution of antibiotic growth promoters allows to achieve ADG and FI comparable to the group with antibiotic supplementation. Korneagy et al. (1995) suggested that improvement in growth performance will be marginal during optimal rearing and feeding conditions and probiotics are more effective in animals during microflora development or when microflora stability is impaired. The efficacy of addition of materials might be influenced by the age and rearing regimes of pigs. In comparison to the antibiotic group, the addition of $B$. subtilis or/and yeast culture significantly increased the EE digestibility of weaned piglets. Jørgensen et al. (2016) indicated that the improvement in fat digestibility might be associated with the improved growth performance observed by dietary supplementation of Bacillus-based probiotic during the grower period. The serum biochemical indicators and immune parameters play an important role in the evaluation of the metabolism and immune status of animals. Previous studies reported that probiotics could stimulate the immune system by increasing the production of antibodies and activation of lymphocytes (Ng et al., 2009). Results from the present study showed that the concentration of $\operatorname{IgA}$, $\mathrm{IgG}$ and $\mathrm{IgM}$ was no significant difference among the four groups. Kim et al. (2014) reported similar results that the addition of probiotics had no effect on serum immunoglobulins concentrations. The difference of bacterial strain, addition level and growth stage of pigs might be the causes leading to such distinction.

The mammalian intestine is colonized by trillions of microorganisms and most of which are bacteria that have co-evolved with the host in a symbiotic relationship (Kamada et al., 2013). The microbiota is a significant source of both nutritional metabolites and inflammatory innate immune signals (Gareau et al., 2010). The findings of the present study revealed that Firmicutes, Bacteroidetes and Proteobacteria are the dominant phyla in $\mathrm{CON}$, BS and BY groups, which is in agreement with the previous studies in which Bacteroidetes and Firmicutes were numerically the most dominant phyla in the microbiome of terrestrial mammals (Levy and Marshall, 2004). Unlike in the groups with the addition of the examined supplements, Lactobacillus was the third dominant genus in the faecal of control group. This is in accordance with the previous studies stating that probiotics promoted the gastrointestinal colonization of beneficial bacteria and decreased the beneficial bacteria excreted in animal manure (Arena et al., 2014). The positive response to yeast in diet fed to swine may be a result of the ability of yeast to suppress the concentration of coliform bacteria in the intestinal tract of weanling piglets (White et al., 2002). Microorganisms such as enterotoxigenic Escherichia coli, Salmonella, Streptococcus, Treponema and Roseburia are agents potentially causing scours from weaning up to the end of fattening period. What's more, increased abundance of Roseburia is associated with weight loss and reduced glucose intolerance in mice (White et al., 2002). Results from the present study showed that addition of $B$. subtilis or/and yeast culture exhibits the same health-promoting effect as in group with antibiotic addition confirmed by the unchanged level of excreted Streptococcus, Treponema and Roseburia in faeces.

\section{Conclusions}

Dietary supplementation of Bacillus subtilis or yeast culture can improve the growth performance of the weaned piglets to the level similar to antibiotics, which can be connected with the increased digestibility of ether extract. B. subtilis or yeast culture can also ensure intestinal health by promoting the excretion of harmful bacteria with piglet faeces. It could be concluded that $B$. subtilis or yeast culture could be used as a substitute for antibiotics and so be applied to the rearing of weaned piglets. However, the usage of their combination in the examined proportion did not enhance the effect, so the coefficient optimum proportion needs to be optimized in further research.

\section{Acknowledgements}

This study was supported by the Earmarked Fund for Beijing Swine Industrialization Innovation Consortium of Agriculture Research System (BAIC-02).

\section{References}

Alexopoulos C., Georgoulakis I.E., Tzivara A., Kritas S.K., Siochu A., Kyriakis S.C., 2004. Field evaluation of the efficacy of a probiotic containing Bacillus licheniformis and Bacillus subtilis spores, on the health status and performance of sows and their litters. J. Anim. Physiol. Anim. Nutr. 88, 381-392, https:// doi.org/10.1111/j.1439-0396.2004.00492.x 
AOAC, 1990. Official Methods of Analysis of the Association of Official Analytical Chemists. $15^{\text {th }}$ Edition. Arlington, VA (USA)

Arena M.P., Caggianiello G., Fiocco D., Russo P., Torelli M., Spano G., Capozzi V., 2014. Barley $\beta$-glucans-containing food enhances probiotic performances of beneficial bacteria. Int. J. Mol. Sci. 15, 3025-3039, https://doi.org/10.3390/ijms15023025

Barton M.D., 2000. Antibiotic use in animal feed and its impact on human health. Nutr. Res. Rev. 13, 279-299, https://doi. org/10.1079/095442200108729106

Benyacoub J., Czarnecki-Maulden G.L., Cavadini C., Sauthier T., Anderson R.E., Schiffrin E.J., von der Weid T., 2003. Supplementation of food with Enterococcus faecium (SF68) stimulates immune functions in young dogs. J. Nutr. 133, 1158-1162, https://doi.org/10.1093/jn/133.4.1158

Canning P., Ruston C., Madson D. et al., 2017. Effect of direct-fed microbial Bacillus subtilis C-3102 on enteric health in nursery pigs after challenge with porcine epidemic diarrhoea virus. J. Swine Health Prod. 25, 129-137

Caporaso J.G., Kuczynski J., Stombaugh J. et al., 2010. QIIME allows analysis of high-throughput community sequencing data. Nat. Methods 7, 335-336, https://doi.org/10.1038/nmeth.f.303

Chattopadhyay M.K., 2014. Use of antibiotics as feed additives: a burning question. Front. Microbiol. 5, article ID 334, https:// doi.org/10.3389/fmicb.2014.00334

Dong T., Feng Q., Liu F., Chang L.K., Zhou X., Han M., Tian X., Zhong N., Liu S., 2017. Alteration of stomach microbiota compositions in the progression of gastritis induces nitric oxide in gastric cell. Exp. Ther. Med. 13, 2793-2800, https:// doi.org/10.3892/etm.2017.4373

Edgar R.C., 2013. UPARSE: highly accurate OTU sequences from microbial amplicon reads. Nat. Methods 10, pp. 996-998, https://doi.org/10.1038/NMETH.2604

Estrada-Angulo A., Valdés Y.S., Carrillo-Muro O., Castro-Perez B.I., Barreras A., López-Soto M.A., Plascencia A., DávilaRamos H., Rios F.G., Zinn R.A., 2013. Effects of feeding different levels of chromium-enriched live yeast in hairy lambs fed a corn-based diet: effects on growth performance, dietary energetics, carcass traits and visceral organ mass. Anim. Prod. Sci. 53, 308-315, https://doi.org/10.1071/AN12192

Favero A., Ragland D., Vieira S.L., Owusu-Asiedu A., Adeola O., 2014. Digestibility marker and ileal amino acid digestibility in phytase-supplemented soybean or canola meals for growing pigs. J. Anim. Sci. 92, 5583-5592, https://doi.org/10.2527/ jas.2014-7919

Gareau M.G., Sherman P.M., Walker W.A., 2010. Probiotics and the gut microbiota in intestinal health and disease. Nat. Rev. Gastroenterol. Hepatol. 7, 503-514, https://doi.org/10.1038/ nrgastro.2010.117

Hansen H.H., El-Bordeny N.E., Ebeid H.M., 2017. Response of primiparous and multiparous buffaloes to yeast culture supplementation during early and mid-lactation. Anim. Nutr. 3, 411-418, https://doi.org/10.1016/j.aninu.2017.08.005

Hung A.T., Lin S.-Y., Yang T.-Y., Chou C.-K., Liu H.-C., Lu J.-J., Wang B., Chen S.-Y., Lien T.-F., 2012. Effects of Bacillus coagulans ATCC 7050 on growth performance, intestinal morphology, and microflora composition in broiler chickens. Anim. Prod. Sci. 52, 874-879, https://doi.org/10.1071/ AN11332

Jørgensen J.N., Laguna J.S., Millán C., Casabuena O., Gracia M.I., 2016. Effects of a Bacillus-based probiotic and dietary energy content on the performance and nutrient digestibility of wean to finish pigs. Anim. Feed Sci. Technol. 221, 54-61, https:// doi.org/10.1016/j.anifeedsci.2016.08.008
Kaewtapee C., Burbach K., Tomforde G., Hartinger T., CamarinhaSilva A., Heinritz S., Seifert J., Wiltafsky M., Mosenthin R., Rosenfelder-Kuon P., 2017. Effect of Bacillus subtilis and Bacillus licheniformis supplementation in diets with low- and high-protein content on ileal crude protein and amino acid digestibility and intestinal microbiota composition of growing pigs. J. Anim. Sci. Biotechnol. 8, article ID 37, https://doi. org/10.1186/s40104-017-0168-2

Kamada N., Seo S.-U., Chen G.Y., Núñez G., 2013. Role of the gut microbiota in immunity and inflammatory disease. Nat. Rev. Immunol. 13, 321-335, https://doi.org/10.1038/nri3430

Kim K.H., Ingale S.L., Kim J.S., Lee S.H., Lee J.H., Kwon I.K., Chae B.J., 2014. Bacteriophage and probiotics both enhance the performance of growing pigs but bacteriophage are more effective. Anim. Feed Sci. Technol. 196, 88-95, https://doi. org/10.1016/j.anifeedsci.2014.06.012

Kiros T.G., Derakhshani H., Pinloche E., D'Inca R., Marshall J., Auclair E., Khafipour E., Van Kessel A., 2018. Effect of live yeast Saccharomyces cerevisiae (Actisaf Sc 47) supplementation on the performance and hindgut microbiota composition of weanling pigs. Sci. Rep. 8, article ID 5315, https://doi.org/10.1038/s41598-018-23373-8

Kornegay E.T., Rhein-Welker D., Lindemann M.D., Wood C.M., 1995. Performance and nutrient digestibility in weanling pigs as influenced by yeast culture additions to starter diets containing dried whey or one of two fiber sources. J. Anim. Sci. 73, 1381-1389, https://doi.org/10.2527/1995.7351381x

Lee S.H., Ingale S.L., Kim J.S., Kim K.H., Lokhande A., Kim E.K., Kwon I.K., Kim Y.H., Chae B.J., 2014. Effects of dietary supplementation with Bacillus subtilis LS 1-2 fermentation biomass on growth performance, nutrient digestibility, cecal microbiota and intestinal morphology of weanling pig. Anim. Feed Sci. Technol. 188, 102-110, https://doi.org/10.1016/j. anifeedsci.2013.12.001

Levy S.B., Marshall B., 2004. Antibacterial resistance worldwide: causes, challenges and responses. Nat. Med. 10, S122-S129, https://doi.org/10.1038/nm1145

Li Y., Xu Q., Huang Z., Lv L., Liu X., Yin C., Yan H., Yuan J., 2016. Effect of Bacillus subtilis CGMCC 1.1086 on the growth performance and intestinal microbiota of broilers. J. Appl. Microbiol. 120, 195-204, https://doi.org/10.1111/jam.12972

Millet S., Maertens L., 2011. The European ban on antibiotic growth promoters in animal feed: From challenges to opportunities. Vet. J. 187, 143-144, https://doi.org/10.1016/j.tvjl.2010.05.001

Moore P.R., Evenson A., Luckey T.D., McCoy E., Elvehjem C.A., Hart E.B., 1946. Use of sulfasuxidine, streptothricin, and streptomycin in nutritional studies with the chick. J. Biol. Chem. 165, 437-441

Ng S.C., Hart A.L., Kamm M.A., Stagg A.J., Knight S.C., 2009. Mechanisms of action of probiotics: recent advances. Inflamm. Bowel Dis. 15, 300-310, https://doi.org/10.1002/ibd.20602

NRC (National Research Council), 2012. Nutrient Requirements of Swine. $11^{\text {th }}$ Revised Edition. The National Academies Press. Washington, DC (USA), https://doi.org/10.17226/13298

PeetSchwering C.M.C.V.D., Jansman A.J.M., Smidt H., Yoon I., 2007. Effects of yeast culture on performance, gut integrity, and blood cell composition of weanling pigs. J. Anim. Sci. 85, 3099-3109, https://doi.org/10.2527/jas.2007-0110

Rather M.A., Hassan M.N., Rather M.A., 2012. Phage therapy an effective remedy against drug-resistant bugs and hard to treat bacterial infections - a review. J. Adv. Vet. Res. 2, 140-147

Ren M., Liu C., Zeng X., Yue L., Mao X., Qiao S., Wang J., 2014. Amino acids modulates the intestinal proteome associated with immune and stress response in weaning pig. Mol. Biol. Rep. 41, 3611-3620, https://doi.org/10.1007/s11033-014-3225-3 
Shen Y.B., Piao X.S., Kim S.W., Wang L., Liu P., Yoon I., Zhen Y.G., 2009. Effects of yeast culture supplementation on growth performance, intestinal health, and immune response of nursery pigs. J. Anim. Sci. 87, 2614-2624, https://doi. org/10.2527/jas.2008-1512

Spellberg B., Bartlett J.G., Gilbert D.N., 2013. The future of antibiotics and resistance. N. Engl. J. Med. 368, 299-302, https://doi. org/10.1056/NEJMp1215093

Trckova M., Faldyna M., Alexa P., Sramkova Zajacova Z., Gopfert E., Kumprechtova D., Auclair E., D'Inca R., 2014. The effects of live yeast Saccharomyces cerevisiae on postweaning diarrhoea, immune response, and growth performance in weaned piglets. J. Anim. Sci. 92, 767-774, https://doi.org/10.2527/ jas.2013-6793
Tripathi M.K., Karim S.A., Chaturvedi O.H., Verma D.L., 2008. Effect of different liquid cultures of live yeast strains on performance, ruminal fermentation and microbial protein synthesis in lambs. J. Anim. Physiol. Anim. Nutr. 92, 631-639, https://doi. org/10.1111/j.1439-0396.2007.00759.x

Wang Y., Gu Q., 2010. Effect of probiotic on growth performance and digestive enzyme activity of Arbor Acres broilers. Res. Vet. Sci. 89, 163-167, https://doi.org/10.1016/j. rvsc.2010.03.009

White L.A., Newman M.C., Cromwell G.L., Lindemann M.D., 2002. Brewers dried yeast as a source of mannan oligosaccharides for weanling pigs. J. Anim. Sci. 80, 2619-2628, https://doi. org/10.1093/ansci/80.10.2619 